\title{
LA PARADOJA DEL DERECHO DE AUTOR EN EL ENTORNO DE LA INDUSTRIA MUSICAL FRENTE A LAS NUEVAS TECNOLOGÍAS*
}

\author{
Olenka Woolcott** \\ Germán Flórez ${ }^{* * *}$
}

Fecha de recibido: 11 de abril de 2014.

Fecha de aprobado: 8 de julio de 2014.

Artículo de investigación

Forma de citación: Woolcott, O. \& Flórez, G. (2014). La paradoja del derecho de autor en el entorno de la industria musical frente a las nuevas tecnologías. Revista Prolegómenos. Derechos y Valores, $17,34,13-32$.

\section{Resumen}

Las nuevas tecnologías de la información y especialmente Internet, han impactado en las formas de explotación de las obras musicales, y con ello en la aplicación de las normas de derecho de autor. El artículo aborda la problemática de los derechos de autor en la industria musical frente al entorno digital desde una perspectiva legislativa, jurisprudencial y de la industria misma. Es decir, se trata de indagar sobre las respuestas que ofrece el legislador, nacional e internacional, para la protección efectiva del derecho de autor en la industria musical, afectada por el entorno digital, y la posición que surge en el escenario jurisprudencial en otros sistemas jurídicos para brindar una solución a este problema. La metodología que se emplea consiste en la revisión de la legislación y doctrina nacionales e internacionales, implementando la comparación jurídica, con el fin de identificar arreglos desde otros sistemas jurídicos a este inconveniente.

\section{Palabras clave:}

Derecho de autor, derechos conexos, industria musical, entorno digital, responsabilidad por infracción a derecho de autor.

\section{THE PARADOX OF COPYRIGHT IN THE ENVIRONMENT OF MUSICAL INDUSTRY FACING NEW TECHNOLOGIES}

\begin{abstract}
New information technology and Internet specially have affected the ways of exploitation of musical Works, and application of copiright laws, too. This article deals with the problems of copyright in musical industry facing the digital environment from a legislative, legal and industrial perspective. In other words, it is about seeking the answers offered by national and

\footnotetext{
El presente artículo constituye uno de los productos enmarcados en la investigación que se desarrolla en el Centro de Investigaciones Sociojurídicas de la Facultad de Derecho de la Universidad Católica de Colombia para el periodo 20132014, referente a las "Implicaciones de la implementación del TLC Colombia-Estados Unidos en materia de propiedad intelectual -derecho de autor y derechos conexos y marcas: análisis desde la responsabilidad patrimonial".

** Doctora en Derecho por la Scuola Superiore S. Anna - Pisa, Profesora e Investigadora en la Facultad de Derecho de la Universidad Católica de Colombia.Correo electrónico: olenka.woolcott@gmail.com.

**** Magister en Propiedad Intelectual por la Queen Mary University of London y Profesor e Investigador en la Facultad de Derecho de la Universidad Católica de Colombia. Correo electrónico: germanabogado@gmail.com
} 
international lawmakers for effective protection of copyright in musical industry, affected by the digital environment, and the position that appears in the legal scene from other legal systems in order to give a solution to this problem. The methodology used consists in a revision of national and international legislation and doctrines, implementing legal comparison, in order to identify solutions to this problem from other legal systems.

\title{
Key words
}

Copyright, connected rights, musical industry, digital environment, responsibility for copyright infraction.

\section{A PARADOXA DO DIREITO DE AUTOR NO ENTORNO DA INDUSTRIA MUSICAL FRENTE ÀS NOVAS TECNOLOGIAS}

\begin{abstract}
Resumo
As novas tecnologias da informação e especialmente Internet, tem impactado nas formas de exploração das obras musicais, e com isso na aplicação das normas de direito de autor. $\mathrm{O}$ artigo aborda a problemática dos direitos de autor na indústria musical frente ao entorno digital desde uma perspectiva legislativa, jurisprudencial e da indústria mesma. É dizer, trata-se de indagar sobre as respostas que oferece o legislador, nacional e internacional, para a proteção efetiva do direito de autor na indústria musical, afetada pelo entorno digital, e a posição que surge no cenário jurisprudencial noutros sistemas jurídicos para brindar uma solução a este problema. A metodologia que é empregada consiste na revisão da legislação e doutrina nacionais e internacionais, implementando a comparação jurídica, com o fim de identificar arranjos desde outros sistemas jurídicos a este inconveniente.
\end{abstract}

\section{Palavras chave}

Direito de autor, direitos conexos, indústria musical, entorno digital, responsabilidade por infração a direito de autor.

\section{INTRODUCCIÓN}

Las obras musicales son sin duda una de las categorías de obras más importantes para el derecho de autor. Desde hace muchos años los autores musicales ejercieron gran influencia en el proceso de reivindicación de los derechos de autor. Sin embargo cabe anotar, que en el reconocimiento otorgado a los autores a partir del Convenio de Berna para la protección de obras literarias y artísticas de 1886 , solo se cobijó a los autores tanto de las letras como de la música de las canciones, dejando excluidos a los intérpretes de obras musicales, a quienes recién a partir de la suscripción del Convenio de Roma de 1961 se les reconoció dichos derechos ${ }^{1}$ con la denominación de derechos conexos o derechos vecinos (Ríos, 2011). Esta situación obedecía al hecho de que, hacia comienzos del siglo $\mathrm{XX} y$ en los años que precedieron, las interpretaciones musicales no podían conocerse más que por interpretaciones en vivo, cajas de música, los órganos y por pianos mecánicos (Pierre, 1986). El desarrollo tecnológico del siglo XX tiene efectos

La Convención de Roma de 1961 o Convención Internacional sobre la Protección de los Artistas, Intérpretes o Ejecutantes, los Productores y los Órganos de Radiodifusión fue aprobada el 26 de octubre de 1961 en la conferencia diplomática que se celebró en Roma y entró en vigor el 18 de mayo de 1964. 
en el campo de la música, lo que se evidenció inicialmente en Estados Unidos a través de los rollos de pianos ${ }^{2}$, los cuales se tocaban sin necesidad de un intérprete o autor, así que los productores de rollos de pianos para esa época empleaban las obras de los autores y compositores en sus rollos y no pagaban las regalías por derecho de autor. Ante dicha situación, los autores instauraron varias demandas judiciales en contra de los productores de pianos, que finalizaron en el primer esquema de licenciamiento obligatorio de obras musicales consagrado en el Copyright Act de 1909 de los Estados Unidos (Izquierdo, 2012).

Después se produjeron nuevos logros de la tecnología, tales como, los casetes, el videocasete y su magnetoscopio, el videodisco, el disco compacto (Pierre, 1986), el DVD, los ordenadores, Internet, el formato MP3, entre otros, todos los cuales posibilitaron que un número creciente de obras se encuentre a disposición del público (De Icaza, 2007) y por ende, los conflictos entre titulares del derecho de autor y los distribuidores de estos medios tecnológicos también aumentaron. En esta nueva óptica, la Convención de Roma apuntó a reglamentar la protección internacional de derecho de autor, respecto a los medios técnicos destinados a fijar, reproducir y difundir obras y presentaciones artísticas (Mille, 1986).

En paralelo y también con el impulso de las nuevas tecnologías, la industria musical se convierte en una importante fuente de ingresos para las naciones en las que esta forma de expresión cultural adquiere un alto nivel de explotación, alcanzando en los países desarrollados su máxima expresión (Thorsby, 1996). Este progreso no habría tenido el mismo auge de no

\footnotetext{
2 "Un rollo de piano es un medio de almacenamiento de música utilizada para hacer funcionar un reproductor de piano, pianista o reproducción de piano. Un rollo de piano es un rollo continuo de papel con perforaciones troqueladas en ella. Las perforaciones representan los datos de control de notas. El rodillo se mueve más de un sistema de lectura conocido como 'rastreador de bar' y el ciclo de reproducción de cada nota musical se activa cuando una perforación atraviesa la barra y se lee" (Portal web Centro de Artigo, 2014).
}

haberse acompañado del reconocimiento de derechos de propiedad intelectual ${ }^{3}$.

En efecto, el campo del derecho de autor sobre la industria de la música constituye otro espacio de las actividades humanas, que se ha visto impactado de manera particular con la incursión de las nuevas tecnologías de la información. Como veremos en el presente escrito, la tecnología -y en especial Internet- es, por una parte, un gran logro para facilitar la vida y las actividades de los seres humanos, pero tenemos que reconocer que, por otra, es un alto riesgo para las sociedades, pues genera desequilibrios en cuanto a la implementación de las medidas que se tendrán que adoptar para adecuarnos a los nuevos tiempos.

Y en este proceso de adaptación no solo se involucra la voluntad individual y colectiva, sino también las reales posibilidades para hacer frente a los desafíos que plantean los actuales tiempos de la tecnología, siendo aquí precisamente en lo que radicará la diferencia entre los Estados que, a través de una determinada cultura y circunstancias, tendrán que poner en marcha las políticas de adaptación de acuerdo con lo que en cada Estado sea posible implementar, ya sea desde las propias políticas públicas o desde una reacción de la industria misma para hacer efectiva la protección de los derechos de autor.

El presente artículo pretende identificar los principales efectos que ha tenido el uso de Internet en la industria musical, entre los más relevantes: el incremento de la piratería en línea $-y$, por ende, el no pago de derechos de autor de obras musicales-; y los cambios de paradigma en el desarrollo de esta industria, con lo cual, nos será posible individualizar las múltiples respuestas que provienen del derecho, tanto del orden nacional como internacional, así como desde la propia industria.

\footnotetext{
A manera de ejemplo podemos ver los ingresos de la ciudad de Salzburgo en la que músicos, compositores, estudios de grabación e inclusive fabricantes de instrumentos generan en la industria musical alrededor de 533 millones de euros y cerca de 9.700 empleos, según un estudio realizado por la Cámara de Economía de Salzburgo en 2013 (Revista Dinero, 20 de agosto de 2013).
} 


\section{EL DERECHO DE AUTOR Y LOS DERECHOS CONEXOS}

El derecho de autor es una disciplina jurídica que por medio de un conjunto de normas, protege los derechos de los creadores de obras artísticas y literarias a través del reconocimiento de una serie de prerrogativas de orden personal y patrimonial llamadas derechos morales y patrimoniales respectivamente (Martínez, 2006). Por otra parte, los derechos conexos son derechos paralelos al derecho de autor y se refieren a la protección de artistas, intérpretes y ejecutantes con relación a sus interpretaciones y ejecuciones; de productores fonográficos respecto de los fonogramas y de los organismos de radiodifusión alrededor de sus emisiones. En algunos países como los Estados Unidos e Inglaterra, los llaman related rights o derechos afines, mientras que en lugares como Francia los llaman droits voisins o derechos vecinos (Ficsor, 2002)

El derecho patrimonial alude a todas las formas conocidas o por conocer, mediante las cuales se realiza la explotación comercial de la obra (Merlero, 2003), y es limitado en el tiempo ${ }^{4}$, en tanto que los derechos morales, guardan la relación personal del autor con la obra, constituyéndose en derechos de tipo personalísimo y por ende inalienables, irrenunciables e imprescriptibles (Rodríguez, 2014). Sobre estos derechos volveremos más adelante, ya que se configuran en la piedra angular sobre la que giran las principales controversias respecto a la protección de los derechos de autor en Internet.

En este mismo sentido, el derecho internacional ${ }^{5}$ junto con las normativas de carácter nacional en

4 En el caso colombiano la protección de los derechos patrimoniales es reconocida por la vida del autor más 80 años.

5 A manera de ejemplo podemos citar entre los principales tratados y acuerdos internacionales suscritos por Colombia los siguientes: Convenio de Berna para la Protección de Obras Artísticas y Literarias de 1886, Convenio de Roma para la Protección de Artistas, Intérpretes o Ejecutantes, Productores de Fonogramas y Organismos de Radiodifusión de 1961, Acuerdos sobre los Aspectos de los Derechos de Propiedad Intelectual relacionados con el Comercio (ADPIC) de 1994, Toda de 1996 y TOIEF de 1996. materia de derecho de autor, ofrece las herramientas para el reconocimiento y protección de los derechos ya referidos, pues de una efectiva protección de los derechos se podrá colegir la existencia, ya sea suficiente o deficiente, de un incentivo a la creación y en consecuencia, un crecimiento de la cultura y la economía (Piedras, 2004).

Por otro lado, ante la relevancia adquirida por la industria creativa, incluida la industria musical, y gracias a la necesidad de una protección efectiva del derecho de autor, se observa que los países cuyas industrias tienen un alto nivel de desarrollo, tienen un gran interés en que las naciones en vías de desarrollo cuenten con los mecanismos de protección necesarios y que estos se apliquen en el entorno digital (Willem, 2010).

En este escenario, se han suscitado encendidos debates en algunos países en vías de desarrollo, terminando en algunos casos en el archivo de proyectos de ley que apuntaban a regular el derecho de autor en el entorno digital ${ }^{6}$. Este tipo de circunstancias perjudica sin duda alguna a los propios autores, pues queda una sensación en la sociedad de que el derecho de autor impide el acceso a la cultura cuando es precisamente todo lo contrario, ya que la protección del derecho de autor se erige en una forma de promover la cultura y de desarrollar la libertad de expresión (Suthersanen, 2008).

Además, teniendo en cuenta que el advenimiento de las nuevas tecnologías de la información facilita la proliferación de la piratería digital. Por la rapidez que Internet impregna a la difusión de contenidos, se produce en la industria musical una

Como ejemplo se cita el caso colombiano que a raíz de la firma del tratado de libre comercio con Estados Unidos, se comprometió a promulgar leyes de protección de derecho de autor en el entorno digital y que después de fuertes debates, terminaron con el archivo de la ley de prestadores de servicios de Internet o la llamada Ley Lleras en el 2011 y con la declaratoria de inconstitucionalidad de la ley 1520/2012 sobre derechos de autor. U. S. Bureau of Labor Statistics. Véase http://industriamusical.es/en-los-ultimos-10-anos-45-de-los-musicosperdieron-su-trabajo/ 
considerable reducción de las ventas de soportes musicales, pues por diversas herramientas en la red resulta posible el acceso a los contenidos musicales de manera gratuita. Según cifras del Departamento de Trabajo de Estados Unidos, la crisis que sufrió la industria musical en los últimos diez años hizo que el $45 \%$ de los músicos perdiera su trabajo en este lapso de tiempo ${ }^{7}$.

La situación descrita que afronta la industria musical ha dado lugar a procesos judiciales cuyos fallos trascendieron al conocimiento público por la repercusión que tienen en el espacio de Internet. En estos procesos, quienes tienen un rol significativo son las asociaciones de editores musicales, que han pretendido frenar de algún modo el fenómeno de la piratería en Internet.

Uno de los primeros casos y quizá paradigmático de los conflictos de intereses que se disputan judicialmente a propósito de Internet, lo constituye Napster. Esta página era una red de intercambio de archivos digitales, también llamada P2P (peer to peer), que gozó de una inmensa popularidad a comienzos de la década pasada, ya que a través suyo los usuarios acudían a un servidor de la misma donde se publicaba la relación de usuarios y archivos que estaban conectados en ese momento, lo que permitía descargar todo tipo de registros, que en su gran mayoría correspondía a material musical protegido por el derecho de autor, sin que sus titulares percibieran algún tipo de retribución económica por dichas descargas. Estas redes P2P son definidas por muchos académicos y expertos en el derecho de propiedad intelectual y nuevas tecnologías de información como una clara arquitectura de red que promueve la piratería y que se presenta como una herramienta que facilita la vulneración de derechos de propiedad intelectual por parte de los usuarios, pues a pesar de que en principio se pueda imaginar que estas redes al compartir los archivos en Internet, están realizando un acto personal, en el fondo efectúan un acto de reproducción de la obra que se encuentra dentro

7 Véase para una información más amplia, U. S. Bureau of Labor Statistics, en http://industriamusical.es/en-los-ultimos10-anos-45-de-los-musicos-perdieron-su-trabajo/ de las potestades exclusivas del ejercicio de los derechos patrimoniales con que cuenta el titular del derecho de autor y que, por ende, requiere de su autorización (Moreno, 2010). Como ejemplos de estas redes están los portales de Internet LimeWire, eMule, Kazaa, Grokster, entre otras.

En el año 2000, reconocidas bandas de rock como Metallica junto con A\&M Records (y otras compañías discográficas), decidieron demandar a Napster por violación de la ley norteamericana de derechos de autor en Internet (Digital Millennium Copyright Act), pretendiendo el resarcimiento de perjuicios por las pérdidas que se ocasionaron con la distribución gratuita de las obras por parte de la página.

El caso fue de conocimiento de District Court y la Corte de Apelaciones del Noveno Circuito de Estados Unidos, quienes optaron por que a pesar de que los usuarios eran los que infringían directamente los derechos de autor, la página tenía culpa de ello, ya que contribuyó a la realización de las infracciones de los derechos. En efecto, era a través del índex o directorio central del portal que los usuarios podían acceder al material protegido sin pagar los derechos de autor (Ríos, 2011). Se consideró que este sitio web incurría en una violación indirecta de los derechos de autor al lucrarse con el acceso de los usuarios que eran receptores de la publicidad generada alli ${ }^{8}$. En consecuencia, Napster tuvo que cesar sus prácticas que animaban la distribución gratuita de las obras musicales protegidas por el derecho de autor, y es así que empezó a cobrar por su servicio de intermediación en la facilitación de contenidos a los usuarios, hasta que en el 2002 cerró definitivamente. Hoy en día Napster es un servicio de música por suscripción ${ }^{9}$.

Países con una industria musical de alto nivel de desarrollo como Estados Unidos, Inglaterra, Francia y España, han tratado de hacer frente

\footnotetext{
$8 \quad$ Véase para mayor información, Corte de Apelaciones de Estados Unidos del Noveno Circuito. A\&M Records, Inc. v. Napster, Inc., 239 F.3d 1004 (2001).

9 Para ampliar la información se puede recurrir al sitio www.naspter.com
} 
a la violación de derechos de autor a través de la dación de leyes que se estiman muy estrictas para con los usuarios infractores de derechos de autor en Internet, sin que hasta el momento se obtengan grandes resultados en cuanto a la disminución de violaciones a los derechos de autor en el entorno digital.

En este sentido, la Ley Hadopi ${ }^{10}$ en Francia contra las descargas ilegales, suscitó gran polémica desde sus inicios, ya que concedía a la Alta Autoridad para la Difusión de Obras y la Protección de Derechos en Internet (Hadopi, por su sigla en francés), la respectiva personalidad jurídica, un poder público independiente y la posibilidad de detectar con ayuda de los prestadores de servicios de Internet a los usuarios que infrinjan derechos de autor en la red, para posteriormente realizar notificaciones a los usuarios en tres etapas: primero se hacía una advertencia vía correo electrónico sobre las sanciones en que el usuario podía incurrir, además de información sobre medidas de seguridad en la red y oferta legal de contenidos. Si el usuario volvía a infringir los derechos de autor en la red, le era enviado por parte de la autoridad una carta certificada advirtiéndole de las penas a que podía ser merecedor. Si aun así incurría nuevamente en violación de derechos de autor, entonces se le podía suspender el servicio de Internet.

Esta facultad se declaró inconstitucional y se determinó que en estos casos, se debía enviar el expediente a un juez penal para que determinara su sanción (Bernal, 2012). Esta ley fue finalmente derogada por el decreto 0157 de 9 de julio de 2013, ya que el Gobierno valoró que los castigos a los usuarios no eran efectivos y en su lugar, propuso adoptar un sistema de oferta de cultura legal para desalentar la piratería, como por ejemplo, en el caso de las obras audiovisuales, que los videos on demand o videos para ser descargados pudieran ser puestos a disposición al poco tiempo de la salida en cartelera de las películas.

10 Se promulgó el 12 de junio de 2009. Consultado en http://www.eldiario.es/turing/Hadopi-descargas-quedaraderogada-Francia_0_132286966.html
En ese sentido, también las leyes Acta $^{11}$ y Sopa ${ }^{12}$ en Estados Unidos, Sinde ${ }^{13}$ en España y Digital Economy Bill ${ }^{14}$ en Inglaterra, han intentado poner fin a las descargas ilegales de material protegido por el derecho de autor, al disponer sanciones a los usuarios que vulneren los derechos de autor en Internet, en parte debido a la presión ejercida por las grandes compañías del entretenimiento que más bien, buscan salvaguardar sus intereses. Sin embargo, tales leyes, que en algunas circunstancias quedaron solo en proyecto -ya que se rechazaron finalmente-, en otros casos como el español, sí vieron la luz, aunque no han sido efectivas y las descargas ilegales de contenidos se siguen produciendo. En este fenómeno han tenido también influencia a través de los debates políticos referidos a los derechos de autor y provisión de contenidos, las compañías de Internet como Google, Facebook, Twitter y otras que han hecho que los usuarios ejerzan una gran presión para el rechazo de estas medidas (Basek, Loengard, White, Giaimo \& Udofia, 2013).

La situación antes descrita nos induce a pensar que como en otros ámbitos del derecho, existiendo la regulación que contempla y sanciona la infracción, prosiguen las conductas transgresoras porque no hallan un mecanismo eficaz que las desaliente, lo que significa que no solo la represión en este campo del derecho de autor y más aún en el espacio de la red, garantiza el cese de las

11 Anti-Counterfeiting Trade Agreement. Este acuerdo impulsado por los Estados Unidos, después de varias rondas de negociaciones fue rechazado finalmente por la Unión Europea en diciembre de 2012.

12 Stop Online Piracy Act o Ley H. R. 3261 fue un proyecto de ley presentado a la Cámara de Representantes de Estados Unidos el 26 de octubre de 2011, y en enero de 2012 se decide suspenderlo indefinidamente hasta obtener mayor consenso.

13 Ley de Economía Sostenible o ley 2/2011 o Ley SindeWert por los apellidos de los últimos ministros de Cultura en España.

14 Esta ley fue promulgada por el Parlamento británico el 20 de noviembre de 2009, recibiendo la aprobación real el 8 de abril de 2010 para entrar en vigor en junio de 2010. Sin embargo, la ley se llevó a revisión judicial por parte de la Corte Suprema de Justicia, quien falló a favor del Gobierno el 20 de abril de 2011, desestimando una apelación presentada por los prestadores de servicios de Internet Talk Talk y BT. 
actividades ilícitas, pues es inminente articular las medidas desde diversos frentes, y no únicamente desde el castigo. Por ello se tiene que involucrar a los sectores educativo y económico con el fin de integrarlos a un solo objetivo: la terminación de infracciones al derecho de autor.

\section{EL DERECHO DE AUTOR Y LA INDUSTRIA MUSICAL}

Cuando hablamos de obras musicales debemos identificar los diferentes actores que participan desde la creación de la obra hasta el momento en que esta se da a conocer al público. Así, la obra musical tiene como creadores al autor de la partitura de la música y de la letra de la canción si la tiene. A estos creadores se les conoce regularmente con el nombre de autor compositor. Dichos compositores de música y letra pueden ser una misma persona o diferentes personas. Sin embargo, la protección otorgada por el derecho de autor es para cada uno de ellos.

La Ley de Derechos de Autor de Colombia o ley 23/1982 establece en su artículo $9^{\circ}$ que "la protección que esta ley otorga al autor, tiene como título originario la creación intelectual", y en el artículo $3^{\circ}$ le concede la facultad exclusiva a este para disponer de su obra a título gratuito $\mathrm{u}$ oneroso en las condiciones que considere pertinentes, facultad que le permite al autor colocar su obra en el mercado a través de las respectivas licencias que darán lugar a los contratos mediante los cuales sus obras circulan hasta llegar a los consumidores.

En el caso de los fonogramas, el artículo $172^{\circ}$ de la citada ley reconoce al productor el derecho de autorizar o prohibir la reproducción directa o indirecta de los mismos, y dispone que cuando un fonograma publicado con fines comerciales, o una reproducción de ese fonograma, se utilice directamente para la radiodifusión o para cualquier otra forma de comunicación al público, el usuario debe abonar una remuneración equitativa y única al productor, destinada a la vez a los artistas intérpretes o ejecutantes y al productor del fonograma.
Una vez se crea la obra musical, existen unos intérpretes o ejecutantes de esta. Tales personas también gozan de una protección especial por parte del derecho de autor a través de la figura de los derechos conexos ${ }^{15}$. Del mismo modo, es común que las obras musicales se graben en formatos análogos o digitales mediante los fonogramas, por lo cual, y en aras de incentivar la inversión privada en el trabajo de los autores musicales, esto es, en la industria musical, el derecho de autor también reconoce ciertas prerrogativas a los productores de fonogramas. Estos derechos se conceden de manera independiente a los que tenga el autor, pero en caso de controversia se aplicarán de forma preferente los que más favorezcan al autor (Ríos, 2011). En las siguientes líneas detallaremos cada uno de los derechos con que cuentan los diferentes tipos de autores en la industria musical, lo que facilitará más adelante, determinar cuál es el grado de afectación de sus derechos por el fenómeno de distribución gratuita de comunicación al público de obras musicales en Internet.

Los autores compositores de una obra musical poseen una serie de derechos de autor que se refiere tanto a los aspectos patrimoniales como a los aspectos morales de estos derechos. Por derechos patrimoniales entendemos aquellos mediante los cuales los autores pueden explotar económicamente su obra (Martínez, Rodrigo y Robayo, Elsa, 2006) En razón al contenido patrimonial de estos derechos, los autores compositores pueden ceder, enajenar, licenciar, etc. la titularidad de los mismos en todo o en parte, según la voluntad del titular de derechos ${ }^{16}$. La ley

15 Estos derechos se empezaron a reconocer a partir de la Convención de Roma de 1961 y son los derechos que tienen los artistas intérpretes y ejecutantes sobre sus ejecuciones, los productores de fonogramas y los organismos de radiodifusión.

16 Recordemos que en el derecho colombiano la titularidad primaria de las obras protegidas por el derecho de autor la tiene precisamente el autor. Consecuentemente una persona jurídica jamás será titular primario de una obra protegida por el derecho de autor en nuestro país. No obstante, las personas jurídicas podrán ser titulares de los derechos de autor sobre las obras por cualquiera de las formas contractuales que la ley autoriza para tal fin, como pueden ser los contratos de cesión de derechos patrimoniales de autor. 
23/1982 y la decisión andina 353/1993 ${ }^{17}$ reconocen a los autores compositores los siguientes tipos de derechos patrimoniales:

El derecho de reproducción de la obra ${ }^{18}$. Es un derecho por medio del cual los autores pueden autorizar o prohibir la fijación de una obra en un soporte material; y realizar copias de este total o parcialmente ya sea por cualquier medio análogo o digital. A partir de los tratados de la OMPI de Internet de $1996{ }^{19}$ y que fueron incorporados en la legislación colombiana desde los años 1999 y $2000^{20}$, se considera que una vez la obra musical se inserta en la memoria o en el disco duro de un computador o Internet, se entiende que se está reproduciendo y por ende siempre se requiere autorización del autor.

El derecho de distribución ${ }^{21}$. Es el derecho que tienen los autores compositores de autorizar o prohibir cualquier tipo de explotación de la obra, ya sea por medio de la figura de la venta, alquiler, arrendamiento o cualquier otra manera a través de la cual se comercialice o se distribuyan los ejemplares de la obra. Esta forma de explotación patrimonial de los derechos de autor se realizaba principalmente mediante las tiendas de ventas de discos. Sin embargo, este derecho, como se verá más adelante, es uno de los que más se afectan con el advenimiento de las nuevas tecnologías de la información, pues la facilidad y el vertiginoso crecimiento que ha tenido la distribución de obras musicales en Internet, se acompañan de la ausencia de pago de derechos a los respectivos

17 La decisión andina 353/1993 establece las normas comunes en derecho de autor para los países del área andina, exceptuando a Venezuela que se retiró en el año 2006.

18 Artículo 13, literal a de la decisión andina 351/1993 y artículos 12, literal a y 76 literal a de la ley 23/1982.

19 Toda y TOIEF de 1996. Estos tratados estuvieron abiertos para la firma hasta diciembre de 1997, para entrar en vigencia tres meses después de que 30 Estados miembros hubieran depositado sus instrumentos de ratificación o adhesión.

20 Colombia ratificó el tratado Toda por medio de la ley $565 / 2000$ y el tratado TOIEF mediante la ley 545/1999. Estos comenzaron a aplicarse a partir del 20 de mayo y el 6 de marzo de 2002, respectivamente.

21 Artículo 13, literal c y d de la decisión andina 351/1993. titulares, circunstancia que lógicamente favorece el decrecimiento acelerado de las ventas de discos. Dicha realidad coloca a la industria de la música, decididamente en la necesidad de buscar nuevas formas de distribución de este tipo de obras. Así surgen precisamente, las tiendas de música en línea y el servicio de streaming.

El derecho de comunicación pública ${ }^{22}$. Es el derecho que tienen los autores de realizar, autorizar o prohibir cualquier tipo de divulgación de la obra musical a una pluralidad de personas reunidas o no en un mismo lugar sin que exista previa distribución de ejemplares de la creación. Este derecho se observa por ejemplo, cuando un establecimiento de comercio enciende la radio o pone música de los artistas para satisfacción de sus clientes. En este caso, los establecimientos y los representantes legales de las compañías que realizan los eventos deben pagar una tasa al autor, a las sociedades de gestión colectiva o a las editoras musicales. Igual aplica cuando la obra musical es comunicada en un evento masivo como un concierto o un suceso deportivo que convoque espectadores. En síntesis, cuando haya una ejecución pública de la música, esta debe ser previamente autorizada por el titular del derecho o sus representantes ${ }^{23}$.

Este derecho también tiene una forma que se ha venido reconociendo en distintas legislaciones desde la proliferación de sistemas para compartir archivos en Internet, llamada "puesta a disposición" y que en Colombia se llegó a reconocer a través de la ley 1520/2012, pero quedó sin efecto por haber sido declarada inexequible por la Corte Constitucional en razón a vicios de for$\mathrm{ma}^{24}$. Este modo de comunicación al público se caracteriza porque los usuarios pueden acceder a la obra musical en cualquier momento y lugar que deseen, como cuando un usuario entra a Internet y descarga una canción para oírla en su dispositivo electrónico.

22 Artículo 15, literal a de la Decisión Andina 351/1993, artículos 12 , literal c y 76 , literal d de la ley $23 / 1982$.

23 Artículos 158 y 159 de la ley 23/1982.

24 Sentencia 011/2013 de la Corte Constitucional de 23 de enero de 2013. M. P. Alexei Julio Estrada. 
El derecho de transformación, modificación o adaptación ${ }^{25}$. Es un derecho por medio del cual el autor tiene la facultad exclusiva de realizar, autorizar o prohibir cualquier metamorfosis, innovación o cambio de la obra. Por ejemplo, cuando una canción que inicialmente fue una balada se lleva al ritmo de salsa o cualquier otro ritmo tropical. Así mismo sucede cuando una canción termina formando parte de la banda sonora de una película.

Además, los autores compositores tienen un conjunto de derechos morales que se asocia directamente con el espíritu que el autor le quiso transmitir a la obra. Estos derechos protegen la personalidad del autor en relación con su obra (Vega, 2003). Es decir, los derechos morales hacen alusión al vínculo intrínseco que el autor posee con la obra que creó. A diferencia de los derechos patrimoniales, tienen la característica de ser inalienables e imprescriptibles. Los derechos morales reconocidos por la ley 23/1982 para los autores son los siguientes:

El derecho de paternidad ${ }^{26}$. Es el derecho que tiene el autor compositor a que siempre y en todo momento se le reconozca como el autor de la obra. Así, aún cuando se conozca al público una obra debe reconocerse la autoría de quien la creó en la forma en que el autor considere, ya sea a través de su nombre o de seudónimos.

El derecho de integridad ${ }^{27}$. Consiste en la potestad que tiene todo autor de que su obra no sea deformada o alterada, de tal suerte que afecte sus intereses y su reputación.

El derecho de ineditud ${ }^{28}$. Derecho que tiene el autor compositor a mantener su obra inédita, es decir, que no dé a conocer su obra al público; o si

25 Artículo 13, literal e de la decisión andina 351/1993, artículos 12 , literal b y 76 , literal b de la ley $23 / 1982$.

26 Artículo 11, literal b de la decisión andina 351/1993 y artículo 30, literal a de la ley 23/1982.

27 Artículo 11, literal c de la decisión andina 351/1993 y artículos 11, literal c y 30, literal b de la ley 23/1982.

28 Artículo 11, literal a de la decisión andina 351/1993 y artículo 30, literal c de la ley 23/1982. quiere que su nombre aparezca o no en aquellos casos en que la obra se da a conocer.

El derecho de modificación ${ }^{29}$. Es el derecho con que goza el autor de realizar los cambios que considere pertinentes después de que la obra se publica. En estos casos de todas maneras el autor debe pagar al editor o al productor los gastos y las pérdidas en que haya incurrido en razón a dicha modificación.

El derecho de retracto o retiro ${ }^{30}$. Es el derecho que tiene el autor de sacar de circulación en cualquier momento su obra o suspender su utilización. Aquí, al igual que en el caso de la modificación, el autor debe indemnizar al editor o al productor por las pérdidas ocasionadas con motivo del retiro de la obra del mercado.

Una vez se trataron los derechos de autor que corresponden al titular de una obra musical, es preciso destacar que el desarrollo de la industria de la música se vincula con el ejercicio de los derechos de propiedad intelectual. En efecto, no solo ha contribuido a dicho progreso el avance tecnológico, sino también la posibilidad de recuperar lo invertido y de obtener ganancias gracias a los derechos de autor, cuya eficacia permite hacer frente al riesgo de la piratería.

La industria musical encuentra justificación en la distribución masiva de las obras, pero siempre que se respeten los derechos de autor, de manera que permanezca en pie el interés por expandir su catálogo de autores, que es la razón de su existencia. Para citar un ejemplo, el índice de i-Tunes supera las 700.000 referencias musicales, incluyendo el acceso a registros que no son nada fáciles de encontrar, como el caso de discos pertenecientes a más de 400 sellos independientes y también títulos exclusivos para i-Tunes, los cuales no aparecen en otras fuentes de distribución (Sandulli, 2004).

El catálogo de autores constituye el capital más importante de la industria musical y está forma-

\footnotetext{
Artículo 30, literal d de la ley 23/1982.

30 Artículo 30 de la ley 23/1982.
} 
do por las licencias de derechos de propiedad intelectual que poseen (Schuster 2014).

En esta industria, confluyen dos intereses, el del empresario por ver mejorados sus ingresos a través de dichas licencias y el de los autores, quienes buscan la difusión de su trabajo. De allí que la relación puede llegar a un punto de tensión, en la medida que la industria pretenda la explotación de los derechos al menor costo posible, frente a lo cual, surge la respuesta del derecho para establecer, vía legislación, los límites de dicha explotación, con el propósito de reafirmar el derecho de autor.

Por otro lado, como todo proyecto empresarial, la industria de la música se encuentra articulada de tal forma, que puede asumir riesgos en la oferta de obras que destina al mercado, lo que sería difícil o hasta imposible asumir para un artista que individualmente motu proprio se dirige al público. He allí otra razón para la existencia de la industria de la música, como apuesta empresarial.

\section{COMPLEJIDAD DE LA INDUSTRIA MUSICAL EN EL MARCO DE LAS NUEVAS TECNOLOGÍAS}

En el contexto de las expresiones culturales, la industria musical es la que tal vez se resiente más por el tremendo impacto que se ocasiona gracias al acelerado desarrollo de la tecnología. Dicha situación, se debe a la facilidad con que se transportan los contenidos auditivos en la red, lo que no tiene parangón con las manifestaciones escritas o audiovisuales. Además, que la naturaleza de las obras musicales determina una fácil aceptación en los hábitos cotidianos de las personas.

Los efectos de la tecnología en la industria de la música pueden examinarse desde dos ángulos: primero, el ángulo de la "aceleración en la difusión de las obras musicales", nos permite visualizar una realidad muy positiva para los autores compositores así como para los intermediarios, desde que los servicios digitales han favorecido una gigantesca difusión de las obras musicales y en general, de contenidos protegidos por derechos de autor y derechos conexos. En efecto, no puede negarse que el fin que buscan los autores compositores como la propia industria musical es dar a conocer la obra al mayor número de personas y auditorios, y con ello el titular o los titulares de derechos de autor y derechos conexos ejercen el derecho de distribución dentro del elenco de derechos antes enunciados. Además, es evidente que este contexto facilitador de la difusión de obras musicales termina beneficiando a los destinatarios finales de la música, sus consumidores.

Un segundo ángulo, que podemos llamar el de la "circulación sin control en la red", en cambio, nos revela que la voracidad con la que puede circular la música en Internet termina siendo incontrolable para los titulares de derechos, pues el entorno digital llega a afectar la propia industria de la música y con ello a dichos titulares, facilitando el uso no autorizado de las obras y grabaciones digitales.

La "circulación sin control" revela consecuencias negativas para la industria musical y para la propiedad intelectual, y exige respuestas desde el derecho y desde la propia industria.

La música como producto de la creación humana requiere de un derecho de propiedad intelectual para circular en el mercado, a través de la respectiva transacción comercial por la cual, el titular recibe una contraprestación económica. El derecho de propiedad intelectual confiere la prerrogativa para exigir autorización previa al uso de la obra, fonograma, con carácter de derecho exclusivo. Así, la obra puede ingresar al mercado donde el titular ejerce el derecho concediendo las licencias u obteniendo la retribución por el uso de esta y ejerciendo control sobre el posible uso no autorizado, que de concretarse esta última conducta en el mercado, el titular del derecho tiene la posibilidad de reaccionar ante la infracción al derecho de autor o derecho conexo.

El escenario descrito es el que se espera de acuerdo con el desenvolvimiento tradicional de 
la industria musical, donde además cabe puntualizar que, si hablamos de industria, estamos ante una organización de recursos humanos y materiales que tiene por fin producir música en todas sus formas para obtener ganancias.

El escenario se transforma totalmente, cuando esa distribución de las obras musicales se realiza vía Internet y con él, vía el complejo entorno digital. He aquí el problema que se pone para el ejercicio del control por parte de los titulares de derechos de autor y conexos y para aquella organización de personas involucradas en obtener las ganancias que esperan de la inversión en la industria de la música.

Estudios revelan que los índices de distribución de música alcanzan a cubrir las demandas desde todo nivel y que es Internet el medio que emplean para acceder a la música ${ }^{31}$. Se evidencia en una investigación realizada en Chile en el 2009, que el incremento en el consumo de la música no representa un aumento de ganancias para la industria y más bien, ha visto bajar sus rendimientos notablemente, lo que es lógico si el mismo estudio revela que la mayoría de los consumidores no pagaron por el uso y disfrute de las obras musicales que consiguieron de Internet.

El caso citado, nos muestra un contexto de difusión de las obras musicales donde resulta imposible ejercitar o hacer valer los derechos de autor y conexos, pues la pregunta nuevamente es, ¿cómo puede el autor llevar el control del uso de sus obras en la red? La realidad es que la industria de la música se afecta directamente por la introducción del entorno digital, y con ella los titulares de derechos de autor y derechos conexos, ven limitados sus derechos a la sola letra de la ley, quedando muy lejos su aplicación en el

31 El estudio fue realizado por el Centro de Estudios de la Universidad de Artes, Ciencias y Comunicación (UNIACC) y una empresa de investigación de mercado, junto con la sociedad de gestión de derechos musicales de Chile: Sintonía Joven, Estudio sobre Música, Comunicación y Jóvenes. Encuesta hecha por Adimark, la UNIACC y la Sociedad Chilena de Derecho de Autor (SCD) en septiembre de 2009 (Schuster, s. f.). entorno digital. En efecto, se trata del vastísimo campo de la red informática que, convirtiéndose en el principal medio de distribución de la música, ha permitido el disfrute de muchos, sin que ello signifique "nuevos derechos para los consumidores" (Shuster, s. f.) observándose un costo muy alto para la industria musical.

Otra consecuencia que ha tenido la irrupción de Internet en la industria de la música, es el cambio en las relaciones entre los autores compositores de música, los servicios, la intermediación y finalmente los consumidores. El entorno digital permite hasta una conexión directa entre el creador de la obra musical y el público, que es el consumidor, lo que desde el punto de vista de las aspiraciones del autor de una obra resulta muy positivo. El panorama sería perfecto si dicho vínculo directo fuera real, sin embargo, la práctica demuestra que el consumo de las obras musicales está en función de la aplicación de los mecanismos utilizados para publicitar las obras y lograr la popularidad del autor. Para ello, no basta colocar la obra en el entorno digital, sino que será necesaria la intermediación de la industria musical en toda la dimensión de la expresión, que tiene que adecuar su actuación al mundo virtual, esto es, no conformarse con los mecanismos tradicionales que venía aplicando antes de la irrupción de Internet, pero tampoco descuidará el concepto de la "promoción del artista" que interesa decididamente a este mismo y por supuesto, a la industria que tiene tras sus hombros, lo que exige evaluar una serie de acciones tradicionales algunas, novedosas otras, como nuevas formas publicitarias en la red, que acompasen la actividad del artista apuntando a su posicionamiento en el mercado de la música.

\section{PROTECCIÓN DE LOS DERECHOS DE AUTOR EN EL ENTORNO DIGITAL}

La efectiva protección de los derechos de autor se erige como uno de los principales retos que la propiedad intelectual debe afrontar en el mundo de las nuevas tecnologías de la información. La facilidad con que los usuarios de Internet pue- 
den tanto transmitir como acceder a todo tipo de contenidos de una manera casi instantánea, es una realidad que nos demanda primero, determinar cuáles de estas conductas pueden constituir una vulneración a los derechos de autor para establecer en qué lugar o jurisdicción se presentan dichas infracciones; y segundo, conocer cuáles son las soluciones que se van planteando para su protección desde el punto de vista tecnológico y jurídico. En este aparte, identificamos algunos de los mayores desafíos que la disciplina autoral encara en el entorno digital, así como las principales posiciones que en el ámbito global se han presentado.

La normatividad internacional de la Ompi nos ofrece desde 1996 un marco general de protección sobre derecho de autor: Tratado de la Ompi sobre Derecho de Autor (Toda) y Tratado de la Ompi sobre Interpretación o Ejecución y Fonogramas (TOIEF) que entraron en vigencia, el primero en marzo y el segundo en mayo del 2002 y se conocieron como los Tratados Internet, precisamente porque instituyeron las normas mínimas de protección de los derechos de autor y conexos en el entorno digital ${ }^{32}$. Con estas regulaciones internacionales se sientan las bases para la protección de los contenidos protegidos por el derecho de autor y las prestaciones intelectuales protegidas por los derechos conexos, y es a partir de ellas que los países miembros deben adecuar sus legislaciones.

Los Tratados de la Ompi recogen en esencia las normas y principios fundamentales de la Convención de Berna de 1886 (Torres, 2008), reglamento internacional que por cierto, no

32 Estos tratados establecen derechos y obligaciones que les permiten a los Estados miembros sentar las bases para proteger los contenidos en el entorno digital. Los puntos que desarrollan estos tratados son fundamentalmente los siguientes: (i) la extensión del derecho de reproducción al ámbito digital; (ii) el nuevo derecho de puesta a disposición de los contenidos; (iii) las obligaciones relativas a las medidas tecnológicas de protección (TPM, por su sigla en inglés); y (iv) las obligaciones relativas a la información para la gestión de derechos de autor (RMI, por su sigla en inglés). Véase un desarrollo de cada uno de estos temas en Torres (2008). pudo imaginar el contexto revolucionario que representarían las nuevas tecnologías frente a los apacibles paradigmas tradicionales de las actividades humanas, y así no pudo vislumbrar su aplicación en la difusión y reproducción de las obras, no obstante, contempló las normas necesarias y vitales para la protección de la creación intelectual. De esta manera, permanecen los criterios para determinar cuándo una obra merece protección y serán los mismos, tanto en el entorno tradicional como en el escenario digital. Así, la originalidad, la protección automática, la salvaguarda a la expresión de las ideas y la no relevancia del mérito ni del destino de las obras permanecen como las directivas de amparo también en el entorno digital.

En ese sentido, los actos que se realicen en el entorno digital concernientes a la reproducción, comunicación pública, digitalización de una obra, almacenamiento en un soporte electrónico, transmisión digital de contenidos protegidos por el derecho de autor a través de las redes digitales, distribución o transformación de una obra, requieren de la autorización del titular, lo que será posible por medio de las licencias de uso o cesión de derechos.

El principio de independencia del derecho patrimonial se aplica de igual modo en estos dos entornos, es decir, que cada una de las modalidades de explotación de una obra protegida por el derecho de autor es autónoma, lo que implica que la autorización de uso o cesión de una de ellas no afecta otras formas de explotación.

\section{COLOMBIA}

Cuando hablamos de los derechos de autor en Internet en Colombia necesariamente tenemos que referirnos a los Tratados de la Ompi de 1996 -Toda y TOIEF-, los cuales como se anotó fueron ratificados por Colombia entre los años 1999 y 2000. La importancia de la ratificación de estos documentos internacionales de derecho de autor radica en la concepción normativa que procura 
una protección de las obras de los autores en el entorno digital. Dentro de los aspectos a resaltar en esta regulación se encuentra el concepto de Internet como un medio a través del cual se comunica y se utilizan las obras y donde los autores deben ejercer derechos exclusivos sobre estas (Vega, 2003).

En este marco legal que ratificó Colombia, se destacan dos modalidades de empleo de las obras: (i) la reproducción de la obra por medio de su digitalización para subirla a Internet y posteriormente (ii) comunicarla al público. Con respecto a la reproducción, se considera que la obra se reproduce desde el mismo momento en que se pasa de un formato análogo a uno digital, por lo que se requiere la autorización exclusiva del autor o del titular de derechos. En lo que tiene que ver con la comunicación pública, podemos observar que cuando la obra se difunde más allá del ámbito privado, doméstico o famliar se debe solicitar también una autorización al titular de los derechos. La gestión de estos derechos en Internet la puede ejercer el titular directamente o por medio de una sociedad de gestión colectiva (Vega, 2003).

Otro de los derechos que se reconoce en el ámbito de Internet es el de la distribución, en cualquiera de sus formas, como la venta o alquiler de las obras musicales, que deben autorizarse por el titular de los derechos. En el entorno digital han aparecido nuevas maneras de distribución legal digital como la tienda musical i-tunes o las compañías de puesta a disposición de obras musicales o streaming musical como Spotify o Deezer, que ya operan en nuestro país a través de intermediarios como la compañía de telefonía móvil Tigo y su plan de Tigo music, que permite a sus usuarios acceder a un catálogo de más de veinte millones de canciones a cambio de un canon mensual, utilizando el sistema Deezer, generando recursos para pagar a los autores.

Colombia no es ajena a las tendencias internacionales a una regulación más estricta en materia de derechos de autor en Internet y tal como ya se señaló, el Gobierno en virtud de la firma del tratado de libre comercio (TLC) con los Estados Unidos intentó mediante el proyecto de ley 241/2011 regular la responsabilidad por las infracciones al derecho de autor y derechos conexos en Internet. Sin embargo y ante la gran polémica que este proyecto de ley generó, el Senado decidió archivar el proyecto en noviembre de 2011.

Una suerte similar ocurrió con la ley 1520/2012 por medio de la cual se cumplían compromisos de adecuación legislativa al TLC con Estados Unidos. El texto regulaba algunos aspectos relacionados con Internet como el reconocimiento expreso al autor del derecho de puesta a disposición del público de la obra, es decir, que el usuario puede tener acceso a la obra en el momento y lugar que considere pertinente pero con respeto del derecho de autor. Si bien esta ley se aprobó, posteriormente fue demandada ante la Corte Constitucional y finalmente declarada inexequible a inicios del 2013 por vicios de procedimiento, sin abordarse el fondo de la ley.

No obstante, cabe anotar que Colombia tiene un gran reto en esta materia, pues el TLC con Estados Unidos se encuentra plenamente vigente y se hace necesaria su reglamentación, ya que como se expresó en el párrafo anterior, es un compromiso adquirido por Colombia que de no acatarlo puede acarrearle las sanciones previstas en el tratado. De todas formas, es importante tener en cuenta los resultados que la introducción de estas leyes han tenido en otras jurisdicciones, para así buscar una norma que guarde un equilibrio entre la protección efectiva de los derechos de autor en la red y los derechos de acceso a la información de los usuarios de Internet.

Abordado el marco referencial normativo en el escenario internacional y nacional, es oportuno ocuparnos de los no menos notorios desafíos que la disciplina autoral debe afrontar, y que hoy constituyen también problemas derivados del uso de Internet en la difusión de contenidos y que por tanto merecen ser referidos de modo especial. 


\section{PROBLEMAS DE JURISDICCIÓN Y COMPETENCIA}

Internet trajo la interconexión de usuarios en todas partes del mundo. Esto precisamente plantea una serie de inconvenientes en el momento en que se presentan infracciones al derecho de autor en lo referente a la determinación de la ley y jurisdicción aplicables para la resolución del caso. En este punto no hay consenso internacional ya que de acuerdo con la jurisdicción se aplican diferentes reglas. Por ejemplo, en los países de la Unión Europea se emplean los tratados firmados por dichos países en virtud de sus políticas de integración ${ }^{33}$. Estos acuerdos multilaterales determinan que para la solución de controversias judiciales entre los miembros de la Unión Europea se debe tener en cuenta si media un contrato, la escogencia de jurisdicción realizada por las partes, en virtud del principio de autonomía de la voluntad. Si no se alude a este aspecto en el contrato, entonces se aplican los siguientes principios: (i) el lugar donde se realizó la aceptación final del contrato ${ }^{34}$; donde se verificó la cláusula de incumplimiento (Hornle, 2009).

En los casos en que no se presente un contrato, lo que constituye el supuesto más común dentro de las infracciones al derecho de autor realizadas a través de Internet, se tiene en cuenta para establecer criterios de jurisdicción y competencia generalmente, el lugar donde la infracción se cometió o el lugar donde se realizó el daño. Sin embargo y aún en las circunstancias en que un juez se avoque al conocimiento de un caso de violación de derechos de autor en Internet, la naturaleza transnacional de este medio de comunicación masivo hace que en ciertas ocasiones los infractores se encuentren en jurisdicciones donde sea difícil hacer cumplir el mandato judicial impuesto por un juez de otra jurisdicción, o sencillamente sea tan costoso que salga más caro el remedio que la enfermedad (Hornle, 2009).

33 Tratados de Bruselas, Roma I y Roma II.

34 Es la llamada postal rule en las legislaciones anglosajonas y se aplica al lugar donde la carta de aceptación del contrato fue despachada. En el entorno digital se referiría al lugar desde donde se envió la comunicación de aceptación del contrato.
Pensemos en un caso en el que una página alojada, que presta servicios de streaming o reproducción de obras musicales, audiovisuales y cinematográficas en línea, su servidor se encuentra en España, la persona que provee el contenido, es decir, donde se instala físicamente está en Estados Unidos y el titular legítimo de los derechos de autor que no ha dado su autorización está en Colombia. Si verificamos los lugares de los agentes involucrados, se observan tres tipos de jurisdicciones aplicables, cada una con diferentes normas sobre protección de derechos de autor.

La protección efectiva de los derechos de autor en Internet genera tales incertidumbres y vacíos que el derecho debe colmar y que solo se pueden suplir a partir de acuerdos internacionales que armonicen la legislación en torno al tema. Por ello, un Estado nacional que pretenda legislar sobre la materia debería primero indagar sobre cuáles son las tendencias globales en derechos de autor e Internet, además de considerar en su ordenamiento los criterios de aplicación de jurisdicción y competencia cuando las infracciones se verifican en otras latitudes.

En ciertos casos y teniendo en cuenta que muchas veces los titulares de derechos de autor son grandes compañías como las disqueras o los estudios cinematográficos -además de las sociedades de gestión colectiva que representan a los distintos titulares de los derechos de autor y derechos conexos-, sucede que dichos titulares pueden ser representados en todo el mundo sin incurrir en altos costos, lo que en cambio sí termina siendo muy oneroso para el autor que no está representado por estas entidades a los fines de entablar las acciones pertinentes para la protección de sus derechos.

\section{CASOS RELEVANTES RELATIVOS A DERECHOS DE AUTOR Y ENTORNO DIGITAL}

A continuación referimos algunos casos (aparte de Napster), que han sido relevantes en materia internacional por su trascendencia, y que ilustran 
el conflicto de intereses en el entorno digital frente a los derechos de autor y la aplicación de la ley correspondiente:

\section{UNIVERSAL MUSIC AUSTRALIA PTY LTD CONTRA SHARMAN LICENCE HOLDINGS LTD, 2005}

Es el caso de un sitio web para compartir archivos llamado Kazaa en Australia. Esta compañía facilitaba a los usuarios el intercambio de material protegido por el derecho de autor y los derechos conexos. La página tenía un aviso en el cual solicitaba a los usuarios no violar los derechos de autor. La Corte determinó que a pesar de las advertencias, estas no eran consecuentes con la actividad del portal, ya que facilitaba a los usuarios obtener copias de obras protegidas por el derecho de autor sin autorización de los titulares del derecho.

\section{VIACOM INTERNATIONAL CONTRA YOUTUBE, 2007}

Aquí el conglomerado estadounidense Video \& Audio Communications (Viacom) demandó por un billón de dólares a la página de Internet Youtube que pertenece a la compañía Google, por permitir que los usuarios del popular portal de videos subieran y pusieran a disposición del público miles de videos musicales pertenecientes a Viacom sin su autorización. Uno de los alegatos de Viacom era que Youtube anima o alienta a sus usuarios a subir los videos a la plataforma y luego los ponen a disposición del público para que otros los puedan ver inmediatamente sin pagar derechos a sus titulares. Igualmente se expuso que Youtube almacena contenido protegido por el derecho de autor en sus servidores sin autorización alguna de sus titulares, para luego poner este contenido a la orden del público (Hinestroza, 2009). En primera instancia, la Corte del Distrito Sur de Nueva York determinó que Youtube no infringió los derechos de autor, ya que cada vez que fue notificado de los videos infractores los eliminó en seguida, de acuerdo con la ley norteamericana de Derecho de Autor (Digital Millennium Copyright Act). En segunda instancia, la Corte de Apelaciones de Nueva York inicialmente estableció que Youtube podría tener conocimiento de las infracciones por unos correos de funcionarios internos del portal. Sin embargo, antes que se decidiera el caso, las partes llegaron a un acuerdo en marzo de 2014.

\section{METRO-GOLDWYN-MAYER CONTRA GROKSTER, 2007}

Este caso perteneciente a los Estados Unidos se refirió a los portales para compartir archivos Kazaa, Grokster y Streamcast. A diferencia del caso Napster, en el presente, no había un directorio central que les posibilitara a los usuarios realizar las descargas directamente del sitio de Internet. La Corte Suprema de Estados Unidos en última instancia, después de que en las instancias anteriores se decidiera que la página de Internet no era infractora de los derechos de autor -por cuanto estos sistemas eran como fotocopiadoras y otros dispositivos que facilitan realizar reproducciones y que con ellos se puede hacer un uso legal o ilegal, recayendo la responsabilidad sobre los usuarios y no sobre los fabricantes del programa-, decidió revertir esta decisión $y$ en su lugar sostuvo que el hecho de poner a disposición elementos tecnológicos que ayuden a promover la violación de derechos de autor por parte de los usuarios, ya que distribuyeron software gratuito con el claro propósito de alentar a los usuarios a intercambiar archivos protegidos por el derecho de autor, trae como consecuencia una responsabilidad por parte del productor del software por inducir a los usuarios a la infracción (Ríos, 2006).

En la actualidad se encuentran pendientes tres casos que tienen una gran trascendencia por el volumen del material infractor y porque las decisiones que se tomen sin duda alguna serán hitos importantes en la protección del derecho de autor en el entorno digital. El primero de esos casos es vKontakte, la principal red social rusa que permite a sus navegadores subir y descargar 
videos, que además pueden ser vistos por otros usuarios sin autorización de los titulares del derecho de autor. Esta compañía fue demandada por Sony Music Russia, Universal Music Russia y Warner Music en el Reino Unido ante la Corte de San Petersburgo y la Corte de Arbitraje por 1,4 millones de dólares.

Otro suceso importante es el del famoso portal Megaupload en Nueva Zelanda, en el que firmas discográficas de Estados Unidos interpusieron una acción penal de extradición contra los fundadores de la página, porque esta animaba a los usuarios a realizar copias ilícitas de material protegido por el derecho de autor, para que a su vez estas se distribuyeran sin licencia alguna, generando pérdidas a las compañías por más de 500 millones de dólares. La sentencia de extradición se que se esperaba para julio de 2014, sin embargo la justicia de Nueva Zelanda aplazó nuevamente el jucio de extradición para febrero de 2015. Una vez se decida el caso, sin duda alguna será un importante precedente en materia de violación de derechos de autor en Internet y el alcance o no de sanciones transnacionales.

Por último está el caso de Pandora, una compañía estadounidense prestadora de servicios de radio en Internet. Esta empresa tiene en su repertorio de música temas que corresponden a canciones anteriores a 1972, año en que cambió la ley de derechos de autor en Estados Unidos, pues a partir de febrero de ese año la protección de propiedad intelectual tomó un carácter federal y antes era de índole estatal, es decir, acorde con las leyes de cada Estado. Las disqueras adujeron en sus demandas, daños ascendentes a más de 60 millones de dólares por el no pago de regalías. Por su parte, Pandora argumentó que antes de 1972 no existía protección de los derechos (Porteiro, 2014).

Estos hechos sin duda alguna, son una referencia significativa para jueces y legisladores que en países como Colombia, empiezan a regular el tema específico de la protección de derechos de autor en Internet, ya que es posible apreciar el alcance que pueden tener las normas vigentes en materia de derecho de autor aplicadas en el entorno digital.

\section{ALGUNAS SOLUCIONES AL PROBLEMA}

Frente a la incertidumbre ocasionada por el uso de las nuevas tecnologías de la información en la difusión de contenidos en el entorno digital $y$ por los pocos resultados que ha tenido la adopción de leyes de protección de derecho de autor en Internet, han sido las propias compañías discográficas, las que respetando el derecho de autor, han ideado formas nuevas de distribución digital de contenidos musicales aplicando las nuevas tecnologías de la información y sobre todo, muy atractivas para los usuarios. En esta línea, destacan los servicios como el streaming o una tecnología de transformación de información multimedia que reproduce la canción a medida que se va recibiendo, sin necesidad de descargar el archivo completo, permitiendo la transmisión y recepción en tiempo real (Álvarez, 2007). Esta técnica de distribución digital, ofrece muchas ventajas a los usuarios, ya que pueden a través de las mismas tecnologías de la información, escuchar los contenidos musicales que deseen sin necesidad de descargar las canciones ni de exponerse a riesgos como los virus o programas maliciosos que pueden contener los archivos descargados de la red.

En este sentido, varias firmas han impulsado un modelo inédito de negocio musical, que se fortalece con las tendencias de los usuarios a la utilización de servicios de consumo de música digital, tales como las tiendas de música en línea como i-Tunes, Prodiscos, las radios digitales personalizadas, los festivales de música en línea y la proliferación de los servicios de streaming con aplicaciones móviles para teléfonos inteligentes y tabletas (Márquez, 2012). Entre estos servicios destacan Spotify, Deezer, Napster, Myspace, Rockola, SoundClick, Ping, Bandcamp, entre otros (Caravaca, 2012).

Estos nuevos modelos de negocio, tienen ante todo como característica principal, el de ser lícitos 
y estar en consonancia con las leyes de derecho de autor, pues acuerdan con los titulares de derechos, un pago por cada vez que un usuario escucha o descarga una canción. En este modelo contractual, existen medios de financiación en dos extremos, por un lado están los sitios que se apoyan exclusivamente en la publicidad, lo que permite la gratuidad del servicio para el usuario, como en el caso de los portales Vevo a través de Youtube y los40.com y por otro lado, los que se basan en el pago de suscripción del usuario como i-Tunes o Mediadownload. También existen modelos mixtos como Spotify donde los servicios más básicos son gratuitos y si el usuario quiere una mayor cobertura o mayor calidad del servicio, entonces paga por estos (Prieto, 2011).

Es preciso anotar que si bien esta no es una solución definitiva al problema de la infracción de los derechos de autor en el entorno digital -ya que como todo sistema tiene sus críticas, por ejemplo, algunos artistas sostienen que las regalías que estos servicios producen son insuficientes-, sí es importante resaltar cómo los servicios de streaming y otros servicios de distribución digital de música, están dando una nueva luz a todos los beneficiarios del derecho de autor sobre cómo proteger sus derechos en Internet y obtener beneficios económicos a partir de la explotación de sus obras.

Según cifras de la Federación Internacional de la Industria Fonográfica (IFPI, por su sigla en inglés) en el 2014 estos servicios digitales ya cuentan con más de 37 millones de canciones disponibles en línea que pagan algún tipo de regalía a sus titulares, lo cual seguramente alentará a los productores discográficos a explorar en profundidad estos territorios inéditos de distribución de obras musicales y obtener provechos tanto para los titulares de derecho como para los usuarios (IFPI, 2014).

\section{CONCLUSIONES}

El desarrollo tecnológico del siglo XX y lo que va del XXI ha producido importantes efectos en el campo de las expresiones culturales, en especial, en la industria musical. Por un lado, generó un progresivo proceso de afectación de los derechos de autor ante el cual, surgió la reacción del derecho para la dación de instrumentos legales internacionales que garantizaran de manera específica los derechos de autor en el contexto virtual. Por otro, las nuevas tecnologías han impulsado el avance de la industria musical pero desde el acompañamiento de las herramientas de protección de los derechos de propiedad intelectual.

Los diferentes tipos de autores que existen en el mundo de la música tienen derechos que pueden verse afectados por la facilidad de la distribución de contenidos a través de Internet.

La evolución de la industria de la música se vincula al ejercicio de los derechos de propiedad intelectual, pues su reconocimiento permite recuperar lo invertido y obtener ganancias merced a los derechos de autor, cuya eficacia hace posible hacer frente al riesgo de la piratería.

El catálogo de autores representa la fuente de recursos más significativa de la industria musical y está formado por las licencias de derechos de propiedad intelectual que posee.

Internet ha facilitado la piratería digital y ello ha determinado una reducción importante de los soportes musicales, lo que deriva en detrimento de los derechos de los autores y consecuentemente, de la industria musical.

Una reacción que se aprecia desde el plano legislativo comparado, frente a la problemática dada por la difusión de contenidos musicales en Internet en violación de derechos de autor, ha sido la dación de leyes dictadas en varios Estados para reprimir la violación de derechos de autor desde dicha modalidad. La experiencia comparada muestra que las medidas legislativas no tienen la relevancia suficiente para lograr reducir la piratería digital, con lo que se demuestra que no solo la represión detendrá el fenómeno de la piratería en Internet, sino que habrá que articular las medidas legislativas con una política 
educativa o acciones generadas en el propio seno de la industria.

En cuanto a los instrumentos internacionales, se dictaron los Tratados de la Ompi de 1996, referidos a la protección de derechos de autor en el entorno digital. Colombia ratificó dichos tratados y son parte de su normatividad interna. Sin embargo, la tendencia internacional legislativa hacia mayor rigor en la sanción de las infracciones en Internet, también estuvo presente en Colombia, aunque sin una verificación concreta en la actualidad. De ello deriva que Colombia tiene un gran reto en esta materia, pues el TLC con Estados Unidos se encuentra plenamente vigente y se hace necesaria su regulación, por tratarse de un compromiso asumido que de no cumplirse puede acarrear responsabilidades para el Estado.

Si bien se cuenta con un marco normativo internacional de protección de derechos de autor por la difusión de contenidos en Internet, que a su vez ha sido ratificado por los países miembros de la Ompi, consideramos de particular relevancia los mensajes transmitidos desde la casuística internacional para la protección de derechos de autor en el ámbito digital, lo que va demostrando que en estos temas de protección de derechos el rol protagónico de los jueces es evidente para el enriquecimiento del derecho de autor, y donde las leyes se configuran en simples pautas que deben ser desarrolladas por la jurisprudencia.

Los casos de Australia y Estados Unidos resultan ilustrativos sobre la forma como se viene dando solución a las infracciones de derecho de autor a través de Internet. Los jueces de dichos Estados, parten de la determinación de la existencia de un derecho de autor que debe respetarse en cada caso y la verificación de su violación a través de conductas permisivas, de una u otra manera, para que los usuarios de contenidos digitales accedan a ellos de manera ilícita. Podemos señalar también que la prueba de dichas conductas se complica cuando ellas se despliegan en el entorno digital, pero sin significar esta realidad, que el derecho de autor se diluye hasta desaparecer. Estos casos evidencian que los magistrados pueden identificar, a pesar de la complejidad que caracteriza la difusión de los contenidos en la red, aquellas conductas poco o nada diligentes de los infractores de derechos de autor, para proteger la incolumidad del derecho, que con dolo o culpa ha sido afectado, con las inevitables consecuencias resarcitorias a que dan lugar.

Las soluciones que hallamos desde el frente jurisprudencial nos muestran que el Internet si bien ha trastocado los planteamientos tradicionales de determinación y reconocimiento de los derechos, también nos exige una adecuación a la era de las nuevas tecnologías, donde los conceptos en la disciplina autoral siguen siendo los mismos, aunque el espacio de su aplicación haya variado ya desde el siglo XX. Y dado que el Internet constituye una herramienta que ha agilizado de manera impresionante las comunicaciones y facilitado la globalización, también así, podrán presentarse las soluciones jurisprudenciales frente a la violación de derechos de autor en el entorno digital, esto es, en el contexto de la globalización. En razón de lo cual, la casuística citada constituye una referencia importante a considerar por los ordenamientos latinoamericanos, como en el caso de Colombia.

Finalmente, la propia industria musical cuyo desarrollo se da en el marco normativo del derecho de autor, también es un referente a tener presente a los fines de articular la protección de los derechos de autor en el ámbito digital.

\section{REFERENCIAS}

Álvarez, I. (2007, 12 de octubre). Streaming al alcance de todos. Recuperado de http://www. iered.org/archivos/Grupo_Vultur/Proyecto_eStreaming/2007-10-12_eStreaming_JSL2007_icalvarez.pdf.

Basek, J., Loengard, P., White, A., Giaimo, C. \& Udofia, I. (2013). United States response to questionnaire concerning collective management of rights. Documentos preparatorios ALAI 2013. 
ALAI 2013, p. 24Recuperado de http://www. alai-usa.org/2013Questionnaire.pdf.

Bernal, E. J. (2012). La protección jurídica de la propiedad literaria y artística en Internet: modelo francés, leyes Hadopi. En: Revista a propiedad inmaterial (332-333). Bogotá. Universidad Externado de Colombia.

Caravaca, R. (2012). La gestión de las músicas actuales. Madrid: Agencia Española de Cooperación Internacional para el Desarrollo (AECID).

De Icaza, M. (2007). Aprender del pasado para crear el futuro: las creaciones artísticas y el derecho de autor. Ginebra: Organización Mundial de la Propiedad Intelectual (Ompi). Recuperado de http:/www.wipo.int/edocs/pubdocs/es/ copyright/935/wipo_pub_935.pdf./

Hinestroza, M. R. (2009). La responsabilidad de los ISP desde el punto de vista de los contenidos. En Revista La propiedad inmaterial (295-302) Bogotá. Universidad Externado de Colombia.

Hornle, J. (2009). The jurisdictional challenge of Internet. .En. Law and the Internet L Edwards. (121-159)Londres: Charlotte.

International Federation of the Phonographic Industry (IFPI). (2014). IFPI Digital music report 2014. Londres: IFPI.

Izquierdo, A. (2012, 12 de abril). Las batallas del derecho de autor. Recuperado de http://andresizquierdo.com/las-batallas-del-derecho-de-autor/

Márquez, I. (2012). Música y materialidad discográfica en la era del acceso. Razón y Palabra, 2-3. Número 79, Mayo-Junio 2012.

Martínez, G. R. (2006). Sobre el derecho de autor. Bogotá: Universidad de la Sabana.

Merlero, R. (2003). Guía práctica sobre los derechos patrimoniales o de explotación (copyright) y su relación con el auto-archivo en repositorios de acceso abierto. Dulcínea. 2003.
Mille, A. (1986). La Convención de Roma ante la evolución de la técnica y el derecho positivo. Boletín de Derecho de Autor. Unesco, 4(4), 21.

Moreno, J. A. (2010). Violación de derechos de autor a través de las redes P2P. En Revista La propiedad inmaterial (265-267). Bogotá. Universidad Externado de Colombia.

Organización Mundial de la Propiedad Intelectual (Ompi). (s. f.). Principios básicos del derecho de autor y derechos conexos. Recuperado de http:// www.wipo.int/export/sites/www/freepublications/ es/intproperty/909/wipo_pub_909.pdf

Piedras, F. E. (2004). ¿Cuánto vale la cultura? Contribución económica de las industrias protegidas por el derecho de autor en México. Conaculta. México D. F.: Caniem.

Pierre, C. (1986). La Convención de Roma, 25 años después. Boletín de Derecho de Autor. Unesco, 4(4), (9-13).

Porteiro, P. (2014, 19 de mayo). Instituto de autor. Recuperado de http://institutoautor.org/story/ VKontakte-Megaupload-y-Pandora-demandadaspor-lesionar-derechos-de-PI_4046

Prieto, M. J. (2011). Música, innovación y propiedad intelectual. ¿Tres mundos irreconciliables? Tres mundos reconciliados. Madrid..Recuperado de: http://api.eoi.es/api_v1_dev.php/fedora/asset/ eoi:78655/componente78654.pdf.

Ríos, W. (2006). Ciberpiratería, "sistemas peer to peer" (P2P). Análisis de las sentencias en los casos Napster, Grokster, Morpheus, StreamCast y Kazaa. En Revista La propiedad inmaterial (8083). Bogotá. Universidad Externado de Colombia.

Ríos, W. ( a 2011). Aspectos generales del derecho de autor y los derechos conexos. La Propiedad Intelectual en la Era de las Nuevas Tecnologías. (3-21)Bogotá. Temis, Universidad de los Andes.

Ríos, W. (b 2011). Ciberpiratería. Sistemas P2P. La propiedad intelectual en la era de las tecnologías. 
La Propiedad Intelectual en la Era de las Nuevas Tecnologías . (625-670)Bogotá. Uniandes-Temis.

Rodríguez, L. (2014, 8 de abril). Contenido del derecho de autor. Derecho moral y derechos patrimoniales. Recuperado de http://www.cadra. org.ar/upload/Miglio_Derecho_Autor.pdf

Suthersanen, U. (2008). El derecho de autor y la libertad de expresión. Actas de las jornadas de la ALAI. Barcelona: ALAI.

Thorsby, D. (1996). El papel de la música en el comercio internacional. Capítulo 12. Recuperado de http://132.248.35.1/cultura/informe/ cap12.2.htm

Vega, A. (2003). Manual de derecho de autor. En Manual de derecho de autor (118-121). Bogotá: Dirección Nacional de Derecho de Autor.

Willem, G. (2010). Transition from guild regulation to modern copyright law. A view from the low countries. Global Copyright Law. Londres: Edward Elgar.

\section{TABLA DE CASOS}

Corte de Apelaciones de Estados Unidos del Noveno Circuito. A\&M Records, Inc. v. Napster, Inc., 239 F.3d 1004 (2001).

MGM Studios, Inc. v. Grokster, Ltd., 545 U. S. 913 (2005), de la United States Supreme Court.

Universal Music Australia Pty Ltd v Sharman License Holdings Ltd, 2005. Federal Court of Australia.

Viacom International, Inc. v. YouTube, Inc., No. 07 Civ. 2103, de la U.S. District Court for the Southern District of New York. 